\title{
Sonoelastrografi ile fokal pankreas kitleleri; fokal pankreatit mi? Pankreatik adonakanser mi?
}

\author{
Pancreatic mass with sonoelastography, fokal pancreatitis or pancreatic adeno ca?
}

\author{
Melike Ruşen METIN ${ }^{1}$, Mustafa TAHTACl² \\ Sağlık Bakanlığı Atatürk Eğitim ve Araştırma Hastanesi, ${ }^{1}$ Radyoloji Bölümü, Ankara \\ Yıldırım Beyazıt Üniversitesi, Tıp Fakültesi, ${ }^{2}$ Gastroenteroloji Bölümü, Ankara
}

\begin{abstract}
Giriş ve Amaç: Ultrasonografi pankreas kitlelerinde kullanışlı bir yöntem olmakla birlikte özellikle kuyruk lokalizasyonundaki lezyonların görüntülenmesinde sınırlıkları vardır ve fokal pankreatik lezyonların benign-malign ayııı tanısına katkısı sınırıdır. Bunun yanı sıra çok kesitli bilgisayarlı tomografi ve manyetik rezonans görüntüleme yöntemleri ile de zaman zaman pankreas kanseri-fokal pankreatit ayırıı tanısında bazı güçlükler yaşanmakta ve bazen biyopsiye ihtiyaç duyulmaktadır. Bu çalışmada kesitsel görüntüleme yöntemleri ile fokal pankreatit-pankreas kanseri açısıdan optimal ayırıı tanı yapılamayan hastalarda transabdominal ultrasonografi ve eş zamanlı sonoelastografi tetkiki yapılarak sonoelastografinin ayıııc tanıya katkısı araştırıldı. Gereç ve Yöntem: Bu çalısmada 2013-2017 tarihleri arasında hastanemizde histopatolojik olarak 52 pankreas kanseri ve 14 fokal pankreatit tanısı alan hastanın sonoelastografi bulguları karşılaştııldı. Bulgular: Pankreatik adenokanser hastalarının yaş ortalaması istatistiksel anlamI olarak fokal pankreatit hastalarından yüksekti. Yine adenokanser hastalarında ortalama serum alfa-fetoprotein seviyesi fokal pankreatit hastalarına oranla anlamlı olarak yüksekti. Fakat lezyonların çaplarında ve sonoelastografide elde edilen gerinim indeksi değerlerinde her iki grup arasında istatistiksel olarak anlamlı fark saptanmadı. Ayrıca adenokanser ve fokal pankreatit arasında renkle kodlanma tipleri açııından anlamlı fark elde edilmedi. Sonuç: Sonoelastografi, mükemmel duyarl-lıkla görüntülenen benign ve malign kitleler arasındaki karekterizasyon ve farklılaşmayı artırabilecek ümit verici bir tekniktir. Fakat bu aşamada pankreatik adenokanser ile fokal pankreatit arasındaki fark açısından henüz sonoelastografinin özgüllüğü düşüktür.
\end{abstract}

Anahtar kelimeler: Elastografi, pankreas, adenokanser, fokal pankreatit

\section{GíRiş}

Ultrasonografi (USG) pankreas kitlelerinde kullanışlı bir yöntem olmakla birlikte özellikle kuyruk lokalizasyonundaki lezyonların görüntülenmesinde sınırlılıkları vardır ve fokal pankreatik lezyonların benign-malign ayırıcı tanısına katkısı sınırıdır (1). Bunun yanı sıra çok kesitli bilgisayarIı tomografi (ÇKBT) ve manyetik rezonans görüntüleme (MRG) yöntemleri ile de zaman zaman pankreas kanse-
Background and Aims: Ultrasonography is a useful method in pancreatic masses, especially in the localization of lesions in the tail, and the contribution to the benign-malignant differential diagnosis of focal pancreatic lesions is limited. In addition, multislice computed tomography and magnetic resonance imaging methods are used to detect pancreatic cancer-focal pancreatitis some difficulties are experienced in the differential diagnosis and sometimes biopsy is needed. In this study, transabdominal ultrasonography and simultaneous sonoelastography were performed in patients who could not undergo an optimal differential diagnosis for focal pancreatitis or pancreatic adeno ca, and the contribution of sonoelastography to differential diagnosis was investigated. Materials and Methods: In this study, sonoelastography findings of 52 pancreatic ca and 14 focal pancreatitis patients were compared histopathologically in our hospital between 2013-2017. Results: The mean age of pancreatic adeno-ca patients was statistically higher than focal pancreatitis patients. The mean level of serum alfafetoprotein was significantly higher in patients with adeno ca than in patients with focal pancreatitis. However, there was no statistically significant difference between the two groups in the diameter of the lesions and strain index values obtained in the sonoelastography. Furthermore, no significant difference was found between adenocarcinoma and focal pancreatitis in terms of color coding types. Conclusion: Sonoelastography is a promising technique to improve the characterization and differentiation between benign and malignant masses displayed with excellent sensitivity. However, at this stage, the specificity of sonoelastography is still low in terms of the difference between pancreatic adenocarcinoma and focal pancreatitis.

Key words: Elastography, pancreas, adeno ca, focal pancreatitis

ri-fokal pankreatit ayırıcı tanısında bazı güçlükler yaşanmakta ve bazen biyopsiye intiyaç duyulmaktadır.

Sonoelastografi (SE) USG probu ile kompresyon ve dekompresyon yöntemleri uygulanarak dokuların elastikiyeti ile ilgili bilgi veren ve malign-benign lezyon ayırıc tanısına katkısı olan bir yöntemdir.

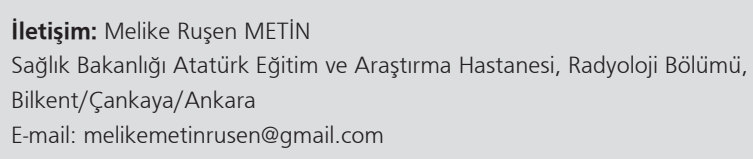

Geliş Tarihi: 20.05.2018 • Kabul Tarihi: 10.08.2018 
SE, ilk kez malign meme lezyonlarının ayırıcı tanısı için kullanılmış ve fibroadenomların skiröz meme kanserlerine göre daha düşük sertlikte olduğu tespit edilmiş (2). Bojunga ve ark., elastografinin tiroid nodüllerinde gereksiz ince iğne aspirasyon biyopsilerinin (IIAB) sayısını önemli ölçüde azalttığını bildirmiştir (3). Sadece tiroid değil, aynı zamanda kas-iskelet sistemi ve intraabdominal organlar artık elastografi ile değerlendirilebilmektedir $(4,5)$. Çeşitli çalışmalarda karaciğerde sertliğe neden olan fibrozis derecesi elastografi ile değerlendirilmektedir (6,7). 2009 yılında Uchida ve arkadaşları ilk kez pankreas hastalıklarında SE'nin kullanımı ile ilgili bir çalışma yapmışlardır (8). Sonraki yıllarda ise kronik pankreatitte erken tanıda SE'nin yeri ve pankreas kitlelerinde benign-malign lezyon ayırıcı tanısıyla ilgili farklı sonuçlar bildiren çalışmalar var$\operatorname{dir}(9,10)$.

Bu çalışmada kesitsel görüntüleme yöntemleri ile fokal pankreatit-pankreas kanseri açısıdan optimal ayırıcı tanı yapılamayan hastalarda transabdominal USG ve eş zamanı SE tetkiki yapılarak SE'nin ayırıcı tanıya katkısı araştırıldı.

\section{GEREÇ ve YÖNTEM}

Bu prospektif çalışma için etik kurul onayı ve yazılı bilgilendirilmiş onam formları elde edildi.

Bu çalışmada 2013-2017 tarihleri arasında hastanemizde histopatolojik olarak 52 pankreas kanseri ve 14 fokal pankreatit tanısı alan hastanın sonoelastografi bulguları karşılaştırıldı. Abdominal radyoloji konusunda 12 yıl deneyimli radyoloji uzmanı tarafından ÇKBT ve MRG tetkikleri ile pankreas kanseri-fokal pankreatit ayırıcı tanısı açısından değerlendirilen hastalara ek olarak real time SE tetkiki yapıldı.

Hastaların, gerçek zamanlı doku elastografi yazılımı ile donatılmış bir dijital sonografi tarayıcısı (Logiq E9, GE Healthcare, Wisconsin, $A B D$ ) ile sırtüstü konumda B modlu ultrason ve SE muayeneleri 5-7,5 MHz multifrekans konveks prob kullanılarak gerçekleştirildi.

Abdominal SE sırasında, hastaya ekspiryum sonrası nefes tutturularak, manuel olarak prob basısı ile kompresyon-dekompresyonlar yapıldı. Fokal pankreatik lezyonlar ve çevre normal yumuşak dokular inceleme alanındaki görüntüleme kutucuğuna (box) kaydedildi. Kompresyon için ortalama basınç 5-7 bar aralık olarak öngörüldü.

SE yapılarak görüntüler USG cihazının hafızasın kaydedildi. Kayıtlardan geri çağrılabilen görüntülerden ilk önce normal cilt-cilt altı yumuşak dokuya ve sonra pankreasa ait fokal lezyondan ilgilenilen alana yönelik (region of interest-ROI) ölçümler alındı (Resim 1) ROI çapı her ölçümde eş tutulmaya çalışıldı ve ölçümler en homojen görüntülenen alandan yapıldı. Renkle kodlama 5 tipe ayrıldı; koyu mavi (T1-sert), mavi- yeşil (T2-orta sert), yeşil (T3-orta yumuşak), kırmızı (T4-yumuşak) ve mikst tip (sarı kırmızı ağırlıkı) (T5) (Resim 2). Kistik lezyonlar görüntülemeye dahil edilmedi.

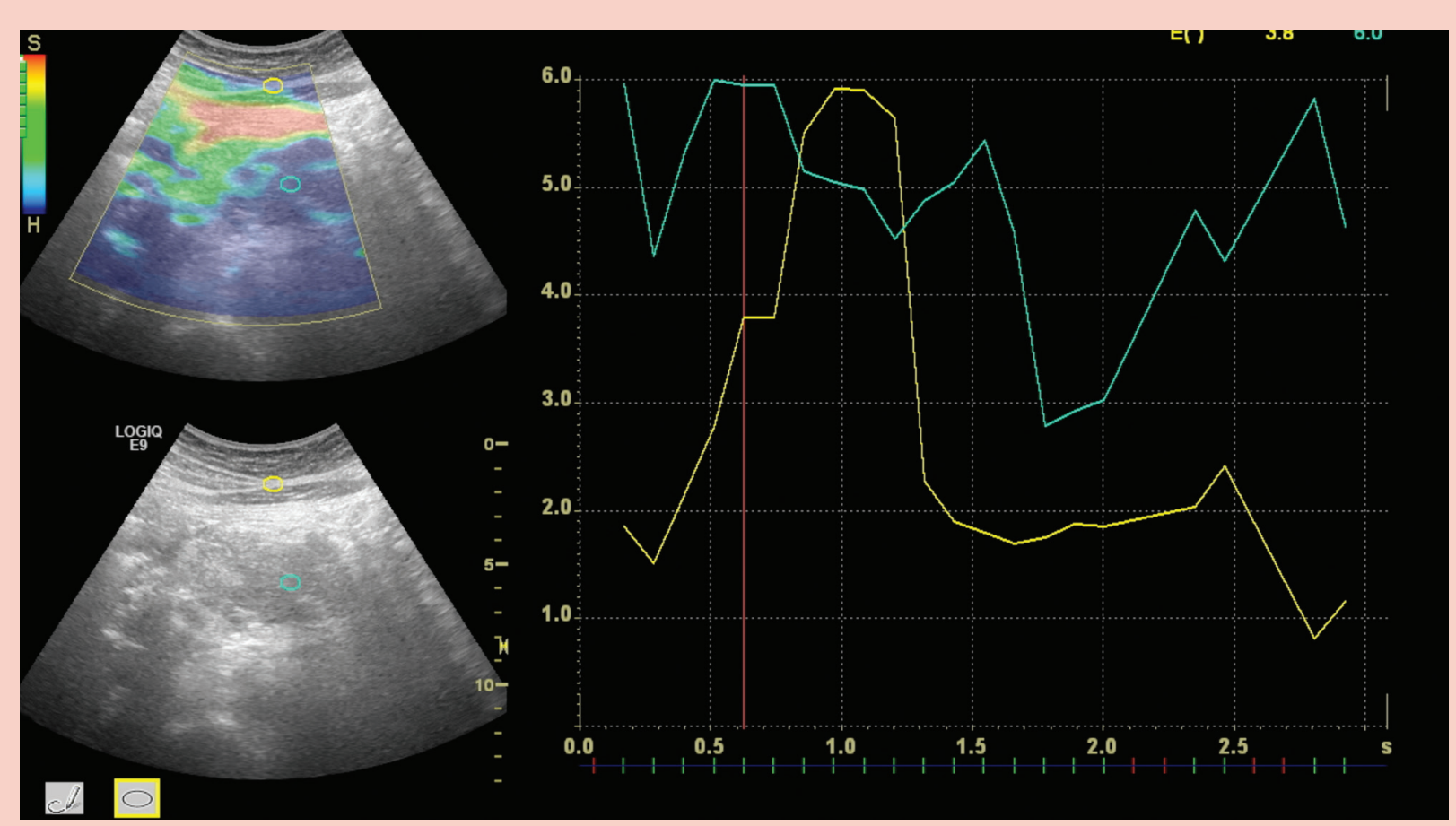

Resim 1. Pankreatik adenokanser tanılı hastada renkle kodlanma paterni Tip 1 patern görüntüsündedir ve Sı değeri $6^{\prime}$ dır. 


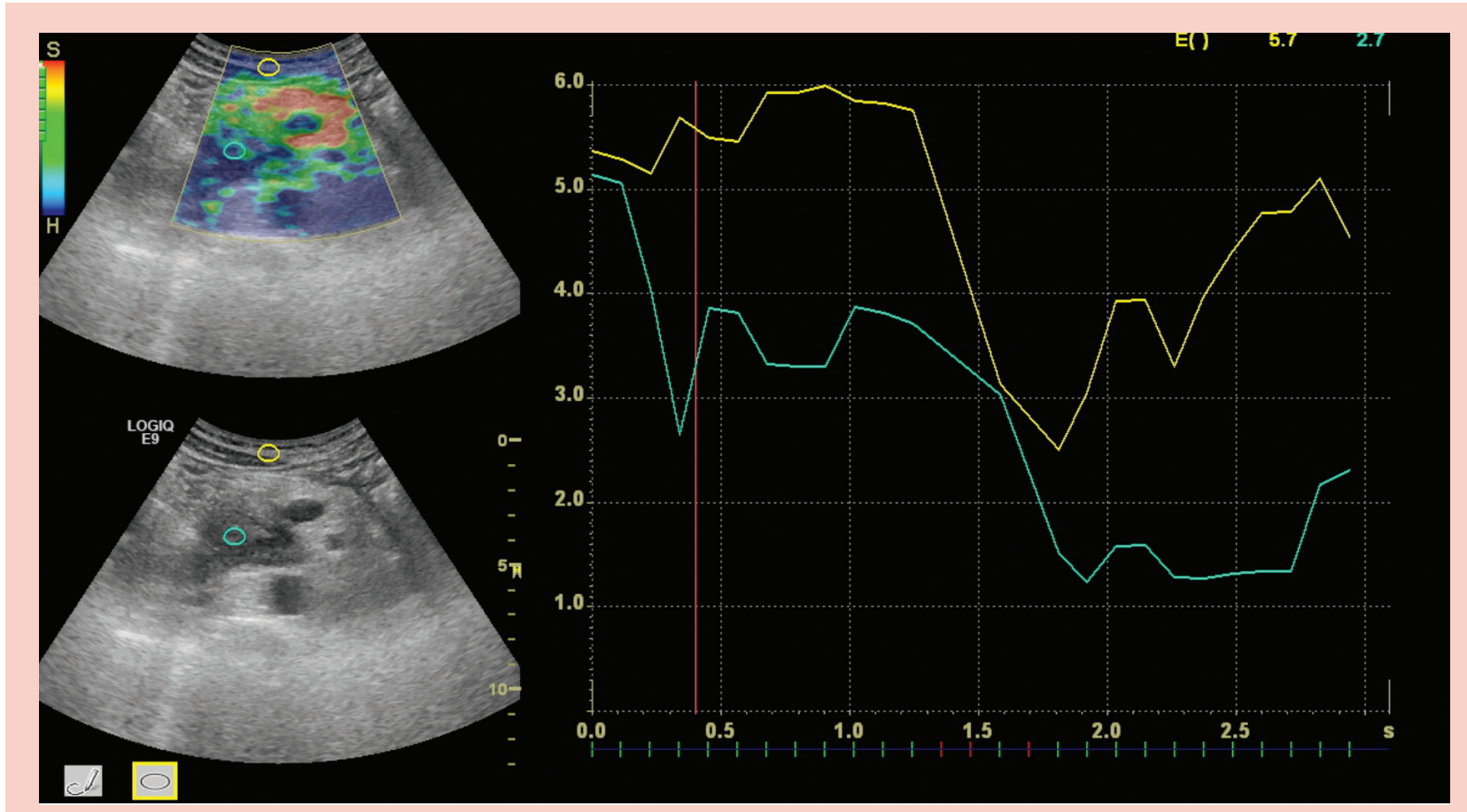

Resim 2. Fokal pankreatit tanılı hastada renkle kodlanma paterni örneği (Tip 2) SI değeri 2.7 olarak ölçülmüştür.

\section{İstatiksel Analiz}

Değişkenlerin dağılım analizi için histogram ve Shapiro-Wilk's testleri kullanıldı. Değişkenler dağılım özelliğine göre sıklık, ortalama土standart hata ve ortanca değerleri verildi. Gruplar arasında kategorik olan değişkenlerin karşılaştırılmasında 'ki kare' ve sürekli değişkenlerin karşılaştırılmasında Mann-Whitney U testleri kullanılarak yapıldı. Elastografinin adenokanser ve fokal pankreatit ayrımında Fisher exact testi uygulandı. İstatistiksel anlam düzeyi $p$ $<0.05$ kabul edildi.

\section{BULGULAR}

Pankreatik adenokanser hastalarının yaş ortalaması istatistiksel anlamlı olarak fokal pankreatit hastalarından yüksekti. Yine adenokanser hastalarında ortalama serum alfa-fetoprotein seviyesi fokal pankreatit hastalarına oranla anlamlı olarak yüksekti. Fakat lezyonların çaplarında ve SE'de elde edilen SI değerlerinde her iki grup arasında istatistiksel olarak anlamlı fark saptanmadı (Tablo 1). Her iki grupta lezyonların en sık görüldüğü lokalizasyon sırasıyla pankreas başı-kuyruk ve gövde idi (Tablo 2).

Tablo 1. Grupların demografik, alfa-fetoprotein ve radyolojik özelliklerinin karşılaştırıması

\begin{tabular}{lccc} 
& Pankreatit $(\boldsymbol{n = 1 4 )}$ & Adenocancer $(\boldsymbol{n = 5 2 )}$ & P değeri \\
\hline Erkek/Kadın & $14 / 0$ & $31 / 21$ & 0.002 \\
\hline Yaş/Yıl & $50.85 \pm 3.13$ & $61.88 \pm 1.71$ & 0,009 \\
\hline Çap & $36.28 \pm 2.57$ & $41.86 \pm 2.69$ & 0,594 \\
\hline Alfafetoprotein* & $45.2(26-337)$ & $245.5(11-201216)$ & 0,034 \\
\hline SI & $4.88 \pm 0.19$ & $4.72 \pm 0.16$ & 0.353
\end{tabular}

SI: Strain Index. *Değişken ortanca ve aralık olarak verilmiştir.

Tablo 2. Lezyon sayı ve lokalizasyonlarının dağılımı

\begin{tabular}{|lcccc|}
\hline & Sayı & Baş & Gövde & Kuyruk \\
\hline Tüm lezyonlar & 66 & $54(\% 81.8)$ & $3(\% 4.5)$ & $9(\% 13.6)$ \\
\hline Adenokanser & 52 & $41 \% 78.8)$ & $3(\% 5.7)$ & $8(\% 15.2)$ \\
\hline Fokal pankreatit & 14 & $13(\% 92.8)$ & 0 & $1(\% 7.1)$ \\
\hline
\end{tabular}


Tablo 3. Elastografi paternleri

\begin{tabular}{|lccccc|}
\hline & Tip 1 & Tip 2 & Tip 3 & Tip 4 & Tip 5 \\
\hline Adeno ca $\mathrm{n}(\%)$ & $39(\% 75)$ & $13(\% 25)$ & 0 & 0 & 0 \\
\hline Fokal pankreatit $\mathrm{n}(\%)$ & $6(\% 42.8)$ & $7(\% 50)$ & $1(\% 7.1)$ & 0 & 0 \\
\hline
\end{tabular}

Fokal pankreatit ve adenokanser grupları elastografi paternleri yönünden değerlendirildi. Adenokanser ve fokal pankreatit grubunda Tip 1 elastografi paterni saptanan olguların oranı sırasıyla \%75, \%42.8 idi. Tip 2 elastografi paterni oranı ise adenokanser ve fokal pankreatitte sırasıyla $\% 25$ ve $\% 50$ idi. Adenokanser ve fokal pankreatit arasında renkle kodlanma tipleri açısından anlamlı fark saptanmadı ( $p=0.089$ ). Her iki hasta grubunda lezyonların tümü elastografi ile görüntülenebildiği için duyarlıık açısından istatistiksel değerlendirme yapılmadı. Tip 3 patern fokal pankreatit grubunda 1 olguda (\%7.1) saptanırken adenokanser grubunda saptanmadı. Tip 4 ve Tip 5 patern her iki grupta da izlenmedi (Tablo 3). Normal pankreas dokusu tüm hastalarda genel olarak yeşil (tip 3) kodlanma paterni göstermekte idi.

\section{TARTIŞMA}

Fokal pankreatit inflamatuvar patoloji olmasına rağmen tıpkı pankreatik adenokarsinomlar gibi fokal kitle görünümünde olabilir. Preoperatif tanıyı doğrulamak çok önemlidir çünkü bu konudaki karışıklık, benign hastalık için majör pankreatik rezeksiyona veya potansiyel olarak opere edilebilecek bir malign lezyon için cerrahinin reddine yol açabilir.

Pankreasta malign kitle düşündüren klinik özellikler ve biyokimyasal parametreler; ileri yaş, sarılık, karın ağrısı, mide çıkış obstrüksiyonu bulguları, belirgin kilo kaybı ve artmış CA 19:9 (300 U/mL'den fazla) seviyesidir (11). Bununla birlikte biyokimyasal parametreler ve görüntüleme bulguları ile de ayırıcı tanı yapılamayabilir. Pankreas kanseri kesin olarak ekarte edilmeden fokal pankreatit tedavisine başlamak da doğru değildir.

Fokal pankreatitte biyokimyasal parametrelerden hastaların bir kısmında saptanan artmış serum immünglobulin G4 (lg G4) (>135 mg/dl) seviyesi, görüntüleme bulguları, steroid tedavisine olumlu cevap ve histomorfolojik bulgular tanıya yardımcı olmaktadır. Fakat pankreas kanserlerinin \%10'unda IgG4 seviyesinin yükseldiği bilinmekte$\operatorname{dir}(12)$. Dite ve arkadaşları yaptıkları bir çalışmada 116 pankreas kanseri tanılı hastanın \%11'inde normalin üstünde ve $\% 6$ sında serum Ig G4 seviyesinin normalin üç katı yükseklikte olduğunu bildirmişlerdir (13). Bizim hasta grubumuzda hastaların büyük kısmında serum Ig G4 se- viyesine bakılmadığı için Ig G4 seviyeleri değerlendirmeye alınmadı.

Fokal pankreatit ile pankreatik adenokarsinomun ayırıc tanısı açısından kullanılan görüntüleme yöntemleri; bilgisayarlı tomografi (BT), manyetik rezonans görüntüleme (MRG) ve pankreatobiliyer ağacı görüntülemek için endoskopik retrograd kolanjiyopankreatografi (ERCP)'dir (14). Ayrıca, manyetik rezonans kolanjiyopankreatografi (MRKP)'nin de ayırıc tanıda yeri bulunmaktadır (15). Endoskopik US (EUS) yöntemi genellikle sedasyon gerektirir, transabdominal US ile karşılaştırıldı̆ında invaziv bir yöntemdir. Histolojik inceleme için pankreasa yaklaşım genellikle zordur.

ÇKBT ile fokal pankreatiti pankreas kanserinden ayırmak bazen imkansız olabilir çünkü tanı kriterleri nerdeyse aynıdır (16). Eğer metastatik lezyon var ise pankreas kanseri tanısı öncelikli olarak düşünülür. MRG ve FDG-PET bu konuda umut verici görüntüleme yöntemleridir. Ayrıca MRG elastografi de özelikle pankreas kanserinmi ekarte etmek için ümit vadeden diğer bir yöntemdir (17). Ampulla wateri seviyesinden alınan biyopside Ig G4 yüksekliği saptanması otoimmün pankreatiti destekler fakat güvenilir bir yöntem değildir $(18,19)$.

Pankreatik adenokanserde belirgin fibrozis ve desmoplastik reaksiyon olduğu bilinmektedir (20). Aynı şekilde fokal pankreatitte de pankreatitin akut ya da kronik evrede olmasına göre değişen derecelerde fibrozis ve atrofi mevcuttur. Daha önce de belirttiğimiz gibi; fokal pankreatit de, kesitsel görüntüleme yöntemlerinde pankreatik adenokanserde de izlenebilen fokal kitlesel lezyon ve pankreatik kanal ve/veya koledokta tıkanma bulgularına neden olabilmektedir. Bu nedenle ayırıcı tanıda güçlükler yaşanmaktadır.

Son zamanlarda, SE, derin doku sertliğini ölçmek için yeni bir yöntem olarak ortaya çıkmış ve sonuçta pankreasın transkutanöz elastografisini daha uygun hale getirmiştir (21). Pankreasta transkutanöz elastografi, EUS elastografiye göre daha az invazivdir ve muayene sırasında hastanın sedasyonunu gerektirmez $(22,23)$.

2015 yllında Japon Tıbbi Ultrasonografi Derneği tarafından pankreasa yönelik elastografi için klinik uygulama kılavuzu yayınlanmıştır. Bu kılavuzda pankreas yönelik ya- 
pılan SE'nin teknik ayrıntıları ve literatürde bulunan son çalışmaların analizleri belirtilmiştir. Bu kılavuz bilgilerine göre SE, yüksek riskli hasta grubunda pankreas kanseri erken tanısı açısından periyodik tarama için aday olabilir (24).

Farklı elastografi türleri vardır; gerilme (strain) elastografisi, akustik radyasyon kuvvet darbesi elastografisi (ARFI), kesme-dalga elastografisi (shear-wave-SWE) ve geçici elastografi (TE) (25-28). Manuel olarak kompresyon ve dekompresyon uygulanarak gerinim indeksi (SI) elde edilir. SI lezyona komşu normal doku ile lezyonun gerinim oranıdır.

$\mathrm{SE}, \mathrm{ROI}$ içindeki ortalama suşa göre hesaplamaları varsayar. Bununla birlikte, tüm durumlarda elastografi hesaplarını etkileyebilecek farklı yakın yapıların varlığı ortadan kaldırılamaz. Kalp, ana damarlar veya omurga gibi çok düşük veya çok yüksek yoğunluk ve sertlik ile yakındaki yapıların varlığı da analiz edilen ROI'den dışlanmakta güçtür. ROI seçimi dikkatli bir şekilde sadece çevredeki yumuşak dokuları içermelidir (29).

Fokal pankreatik lezyonların değerlendirilmesinde transkutanöz veya EUS elastografi ile ilgili olarak, elastografik paternleri analiz eden daha önceki bazı çalışmalar, renk haritasının yorumlanmasının öznelliklerinden ve sensitivite ve spesifitenin yetersiz olmasından dolayı oldukça yetersizdir (30-33).

Uchida ve ark., tek başına B-modlu görüntülerin kullanımıyla karşılaştıııldığında lezyon bulma oranının ve tanı oranının B modu ve elastografik görüntülerin kombine kullanımı ile \%90'ın üzerine çıkabileceğini bildirmiş̧ir (33).

Giovannini ve arkadaşları 92 malign ve 29 bening lezyon ile toplam 121 hastayı kapsayan çok merkezli bir çalışma yürütmüşlerdir ve malign-benign lezyon ayırımında SE'nin yüksek sensitivite ve spesifiteye (sırasıyla \%92.3 ve \%80) sahip olduğunu bildirmişlerdir (34).

Evet SE ile pankreatik lezyonların saptanması; normal doku paternine göre patolojik dokunun farklı renkle kodlanması nedeniyle kolaylaşmaktadır, fakat bizim çalışmamızda pankreas kanseri ile pankreatit arasında gerek elastografik renk kodlanma paterni gerekse SI değerleri arasında anlamlı istatistiksel fark saptanmadı ve literatür taramamızda bu konuda bizim bulgularımızı destekleyen birkaç çalışma mevcuttu. Kawada ve ark. çalışmalarında ortalama gerinim oranını benign kitleler için 4.15, malign kitleler için ise 12.16 olarak bildirmişlerdir. Ancak fark istatistiksel olarak anlamlı değildi ( $p=0.234)$ (35). Jansenn ve arkadaşları yaptıkları çalışmada bizim çalışmamıza benzer şekilde pankreas kanserlerinin çoğunun mavi ve mavi-yeşil bal peteği görünümde olduğunu belirtmişlerdir (36). Kronik pankreatit sklerozan bir hastalıktır ve taş oluşumu ve kalsifikasyonları içerir (37). Skleroz mavi (tip 1) renkli (sert) kodlanmaya neden olmaktadır. Bu da pankreaskanseri ile fokal pankreatitin benzer elastografik paternlere sahip olmasına neden olmaktadır. Bizim çalışmamızda da kronik pankreatitte SE'nin özgüllüğü düşük bulunmuştur. Sevastita ve arkadaşlarının yaptıkları çalışma da bizim bulgularımızı desteklemektedir (38).

Sonuç olarak, SE, mükemmel duyarlılıkla görüntülenen benign ve malign kitleler arasındaki karekterizasyon ve farklılaşmayı arttırabilecek ümit verici bir tekniktir. Fakat bu aşamada pankreatik adenokanser ile fokal pankreatit arasındaki fark açısından henüz SE'nin özgüllüğü düşüktür.

Yakın gelecekte SE'nin pankreas kanseri açısından yüksek risk taşıyan hastalarda tarama testi olarak kullanılabileceği ve fakat bunun için hem teknik çalışmalara hem de geniş hasta serisiyle yapılacak klinik çalışmalara intiyaç olduğu düşünülmektedir.

\section{KAYNAKLAR}

1. Park MK, Jo J, Kwon $\mathrm{H}$, et al. Usefulness of acoustic radiation force impulse elastography in the differential diagnosis of benign and malignant solid pancreatic lesions. Ultrasonography 2014;33:2633.

2. Ophir J, Garra B, Kallel F, et al. Elastographic imaging. Ultrasound Med Biol 2000;26(Suppl. 1):S23-9.

3. Bojunga J, Herrmann E, Meyer G, et al. Real-time elastography for the differentiation of benign and malignant thyroid nodules: a meta-analysis. Thyroid 2010;20:1145-50.

4. Ooi CC, Malliaras P, Schneider ME, Connell DA. "Soft, hard, or just right?" Applications and limitations of axial-strain sonoelastography and shear-wave elastography in the assessment of tendon injuries. Skeletal Radiol 2014;43:1-12.

5. Menzilcioglu MS, Duymus M, Gungor G, et al. The value of real-time ultrasound elastography in chronic autoimmune thyroiditis. Br J Radiol 2014;87:20140604

6. Muller M, Gennisson JL, Deffieux T, et al. Quantitative viscoelasticity mapping of human liver using supersonic shear imaging: preliminary in vivo feasibility study. Ultrasound Med Biol 2009;35:219-29.

7. Arda K, Ciledag N, Aribas BK, et al. Quantitative assessment of the elasticity values of liver with shear wave ultrasonographic elastography. Indian J Med Res 2013;137:911-5.

8. Uchida $\mathrm{H}$, Hirooka $\mathrm{Y}$, Itoh A, et al. Feasibility of tissue elastography using transcutaneous ultrasonography for the diagnosis of pancreatic diseases. Pancreas 2009; 38: 17-22. 
9. Ito $\mathrm{T}$, Ishiguro $\mathrm{H}$, Ohara $\mathrm{H}$, et al. Evidence-based clinical practice guidelines for chronic pancreatitis 2015. J Gastroenterol 2016;51:85-92

10. Shimosegawa $T$, Kataoka K, Kamisawa $T$, et al. The revised Japanese clinical diagnostic criteria for chronic pancreatitis. J Gastroenterol 2010;45:584-91.

11. Bedi MM, Gandhi MD, Jacob G, et al. CA 19-9 to differentiate benign and malignant masses in chronic pancreatitis: is there any benefit? Indian J Gastroenterol 2009;28:24-7.

12. Psarras K, Baltatzis ME, Pavlidis ET, et al. Autoimmune pancreatitis versus pancreatic cancer: a comprehensive review with emphasis on differential diagnosis. Hepatobiliary Pancreat Dis Int 2011;10:465-73. Review.

13. Díte $P$, Uvírová $M$, Bojková $M$,et al. Differentiating autoimmune pancreatitis from pancreatic cancer. Minerva Gastroenterol Dietol 2014;60:247-53. Epub 2014 Oct 7. Review.

14. Manikkavasakar S, AlObaidy M, Busireddy KK, et al. Magnetic resonance imaging of pancreatitis: An update. World J Gastroenterol 2014;20:14760-77.

15. McMahon CJ. The relative roles of magnetic resonance cholangiopancreatography (MRCP) and endoscopic ultrasound in diagnosis of common bile duct calculi: a critically appraised topic Abdominal imaging 2008;33:6-9.

16. Takahashi N, Fletcher JG, Fidler JL, et al. Dual-phase CT of autoimmune pancreatitis: a multireader study. AJR Am J Roentgenol 2008; 190:280-6.

17. Mariappan YK, Glaser KJ, Ehman RL. Magnetic resonance elastography: a review. Clin Anat 2010;23:497-511.

18. Rebours V, Le Baleur $Y$, Cazals-Hatem D, et al. Immunoglobulin G4 immunostaining of gastric, duodenal, or colonic biopsies is not helpful for the diagnosis of autoimmune pancreatitis. Clin Gastroenterol Hepatol 2012;10:91-4.

19. Kim MH, Moon SH, Kamisawa T. Major duodenal papilla in autoimmune pancreatitis. Dig Surg 2010;27:110-4.

20. Korc M. Pancreatic cancer associated stroma production. Am J Surg 2007;194(4 Suppl):s84-s86..

21. Park MK, Jo J, Kwon $\mathrm{H}$, et al. Usefulness of acoustic radiation force impulse elastography in the differential diagnosis of benign and malignant solid pancreatic lesions. Ultrasonography 2014;33:2633.

22. Onur MR, Goya C. Ultrasound elastography: abdominal applications. Turkiye Klinikleri J Radiol Special Topics 2013;6:59-69.

23. Cosgrove D, Piscaglia F, Bamber J, et al. EFSUMB guidelines and recommendations on the clinical use of ultrasound elastography. Part 2: clinical applications. Ultraschall Med 2013;34:238-53.

24. Kawada N, Tanaka S. Elastography for the pancreas: Current status and future perspective. World J Gastroenterol 2016;22:3712-24.
25. Fahey BJ, Nelson RC, Bradway DP, et al. In vivo visualization of abdominal malignancies with acoustic radiation force elastography. Phys Med Biol 2008;53:279-93.

26. $\mathrm{Yu} \mathrm{H}$, Wilson SR. Differentiation of benign from malignant liver masses with acoustic radiation force impulse technique. Ultrasound Q 2011;27:217-23.

27. Nightingale KR, Palmeri ML, Nightingale RW, Trahey GE. On the feasibility of remote palpation using acoustic radiation force. J Acoust Soc Am 2001;110:625-34.

28. Friedrich-Rust $M$, Wunder $K$, Kriener $S$, et al. Liver fibrosis in viral hepatitis: non invasive assessment with acoustic radiation force impulse imaging versus transient elastography. Radiology 2009;252:595-604.

29. Adrian Sãftoiu, Peter Vilman. Endoscopic Ultrasound Elastography - a New Imaging Technique for the Visualization of Tissue Elasticity Distribution. J Gastrointestin Liver Dis June 2006;15:161-5.

30. Janssen J, Schlörer E, Greiner L. EUS elastography of the pancreas: feasibility and pattern description of the normal pancreas, chronic pancreatitis, and focal pancreatic lesions. Gastrointest Endosc 2007;65:971-8.

31. Hirche TO, Ignee $A$, Barreiros AP, et al. Indications and limitations of endoscopic ultrasound elastography for evaluation of focal pancreatic lesions. Endoscopy 2008;40:910-7.

32. Iglesias-Garcia J, Larino-Noia J, Abdulkader I, et al. EUS elastography for the characterization of solid pancreatic masses. Gastrointest Endosc 2009;70:1101-8.

33. Uchida $H$, Hirooka $Y$, Itoh A, et al. Feasibility of tissue elastography using transcutaneous ultrasonography for the diagnosis of pancreatic diseases. Pancreas 2009;38:17-22.

34. Giovannini M, Thomas B, Erwan B, et al. Endoscopic ultrasound elastography for evaluation of lymph nodes and pancreatic masses: a multicenter study. World J Gastroenterol 2009;15:1587-93.

35. Kawada N, Tanaka S, Uehara $\mathrm{H}$, et al. Feasibility of second-generation transabdominal ultrasound-elastography to evaluate solid pancreatic tumors: preliminary report of 36 cases. Pancreas 2012;41:978-80.

36. Janssen J, Schlorer E, Greiner L. EUS elastography of the pancreas: feasibility and pattern description of the normal pancreas, chronic pancreatitis, and focal pancreatic lesions. Gastrointest Endosc 2007;65:971-8.

37. Kloppel G, Detlefsen S, Feyerabend B. Fibrosis of the pancreas: the initial tissue damage and the resulting pattern. Virchows Arch 2004;445:1-8.

38. Iordache S, Costache MI, Popescu CF, et al. Clinical impact of EUS elastography followed by contrast-enhanced EUS in patients with focal pancreatic masses and negative EUSguided FNA. Med Ultrason 2016;18:18-24. 